\title{
Improved management of compressed air energy storage systems
}

\author{
Mahdi Naji Aghakhanloo ${ }^{1 *}$, Mohadese Naji Aghakhanloo ${ }^{2}$ \\ ${ }^{1}$ Department of Energy Engineering, College of Engineering, Mashhad Branch, \\ Islamic Azad University, Mashhad, Iran. \\ ${ }^{1}$ Department of Biology, College of Science, Mashhad Branch, \\ Islamic Azad University, Mashhad, Iran. \\ Mahdinaji.a@mshdiau.ac.ir
}

\begin{abstract}
Because of the importance of energy in the present day, engineers have become more and more focused on designing types of power plants and energy generation systems. Energy storage is a key element in achieving the goals of energy sustainability, which leads to saving energy and cost. Electricity storage in the form of compressed air energy has particular importance amongdifferent way of storage. In the beginning of this paper, the conditions for the production of electrical energy using compressed air, its history, mechanism, structure, disadvantages and advantages are examined. Then the features, conditions for improvement and better management of the compressed air energy storage (CAES) system are studied. Also, general solutions for improving the CAES system and increasing energy quality are suggested.
\end{abstract}

Keywords: energy storage, EES, CAES, energy agementman, loss reduction

\section{Introduction}

Today's energy storage (ES) has reached its stage of development, which can have a significant impact on new technology. ES systems can be significant for the needs of the industry, saving energy, the environment, generating heating and cooling, improving the equipment's lifespan, facilitating the replacement of fuels, improving economic efficiency and saving.

ES systems are not a new concept and it can be said that humans have been seeking energy storage from the beginning, but now with the reduction of fossil fuels and their rising prices and environmental pollution, and also, increasing consumption in different times and seasons and reducing consumption at other times, hasled to the use of these systems more and more and nowadays, we see a lot of investments from governments and companies and research centers in this field, so that they can get the best energy in the best conditions from the aspects of charging time, discharge, size, area, cost, etc. (Dincer and Rosen 2002)

The use of ES systems has following significant advantages:

1. reduce energy costs;

2. reduce energy consumption;

3. Improving air quality in used environments;

4.Increase in flexibility;

5. reduce initial costs and maintenance cost;

6. reduce equipment size;

7. Effective utilization of the equipment;

8. Protecting fossil fuels (by facilitating energy consumption and / or replacing fuels);

9. Reducing emissions of pollution

1.1 Storage advantage

Each type of storage has different benefits. Some of the storage methodscreats sustainability in systems, some csuses shift in peak hours, some generates the power that consumers need and others have a long lifespan, high capacity, low costs.

\subsection{Electrical energystorage}

For many energy technologies, energy storage is a vital aspect.

According to this fact that the most use of electrical energy is in the industrial, residential and service sectors, and their consumption varies from day to day, weekly, and seasonal, it generates produce and demand based on peak hours, which includes more expensive costs and non-peak hours with lower cost. It is also more costly and difficult for the power plants to produce electricity on the peak hours due to the use of conventional gas turbines or diesel generators that burn fossil fuels. Therefore, the Energy Saving System (EES) provides an alternative method for supplying energy demand at peak times. EES systems are known as efficient, environmentally 
friendly and safe systems for energy storage and recycling. Electrical energy storage is defind as "the process of converting electrical energy into another form and using it to distribute and replace electricity at a later time". (McLarnon and Cairns 1989)

Briefly, advantages of EES are included load curve allocation, network stability and frequency control assistance, improvement of power quality, reduced voltage fluctuations, increased efficiency of fossil fuel plants, simultaneous matching of supply and demand, delays in the development of transmission lines, and reliability. (DTI, 2004)

The many problems in the electrical energy storage (EES) cause the development of today's power system technology. Various methods exist for EES in large dimensions, through four methods including chemical method(batteries, hydrogen storage, natural gas storage systems), thermal method (including high temperature storage, tangential thermal and hidden thermal storage), mechanical method (including flywheel, hydro pump and compressed air) and electrical method (including super capacitors and superconductors). (Dincer and Rosen, 2002)

Each EES system has its own characteristics, but an appropriate EES system should have several characteristics:

1. High energy and powerdensity from aspect of mess and volume;

2. Easy integration and development with renewable energy resources and current energy networks;

3. high efficiency; long useful life and reliability of systems and components;

4. Capable of storing energy in large quantities;

5. Measures of energy efficiency after investment;

6.proper charging and discharging (figure 1 and figure 2)

In figure 1 and figure 2, key EES technologies based on the power and size of energy storage in terms of storage and discharge time are shown. (Ellabban, et al. 2014)

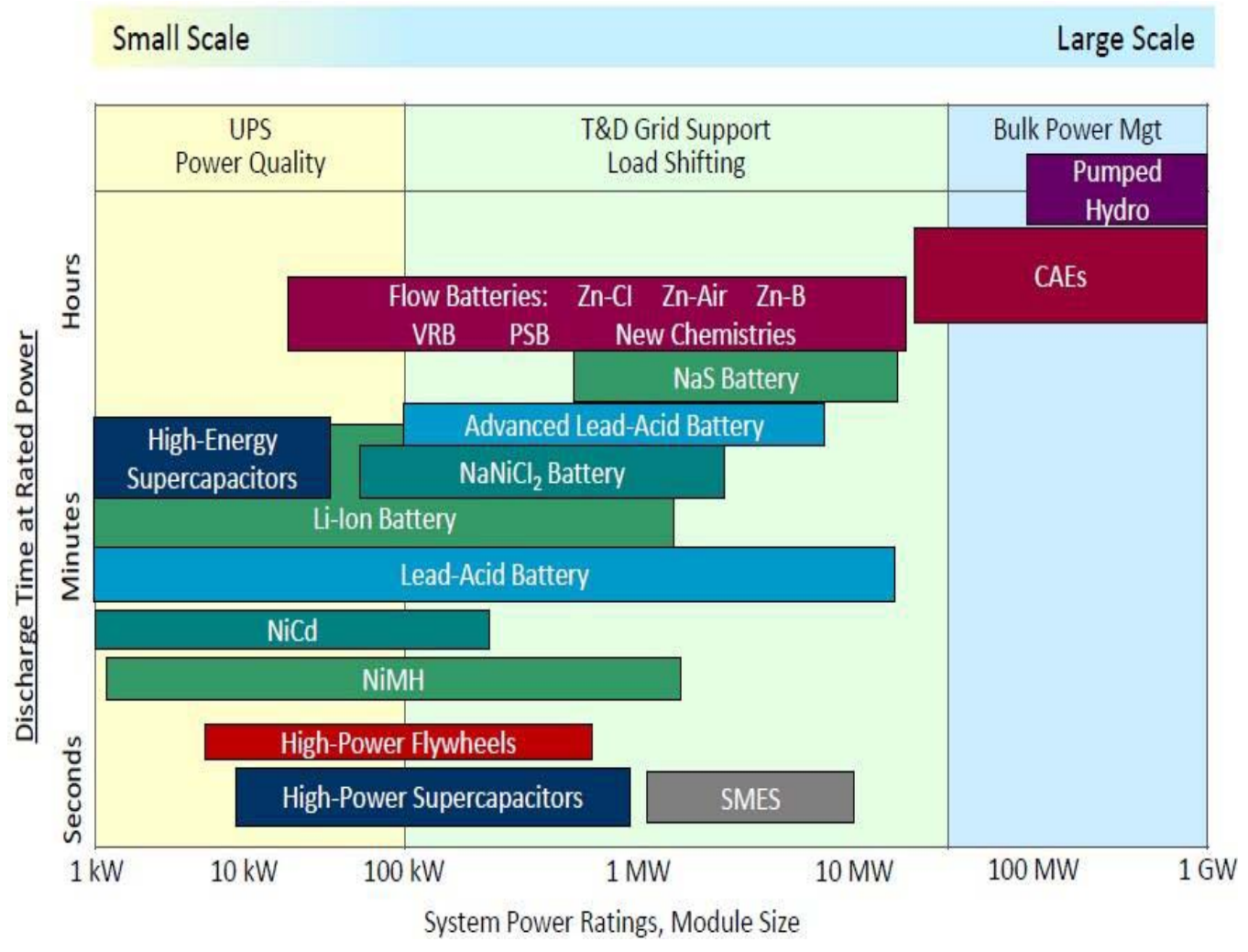

Figure 1 Energy storage technologies in terms of power and discharging time 


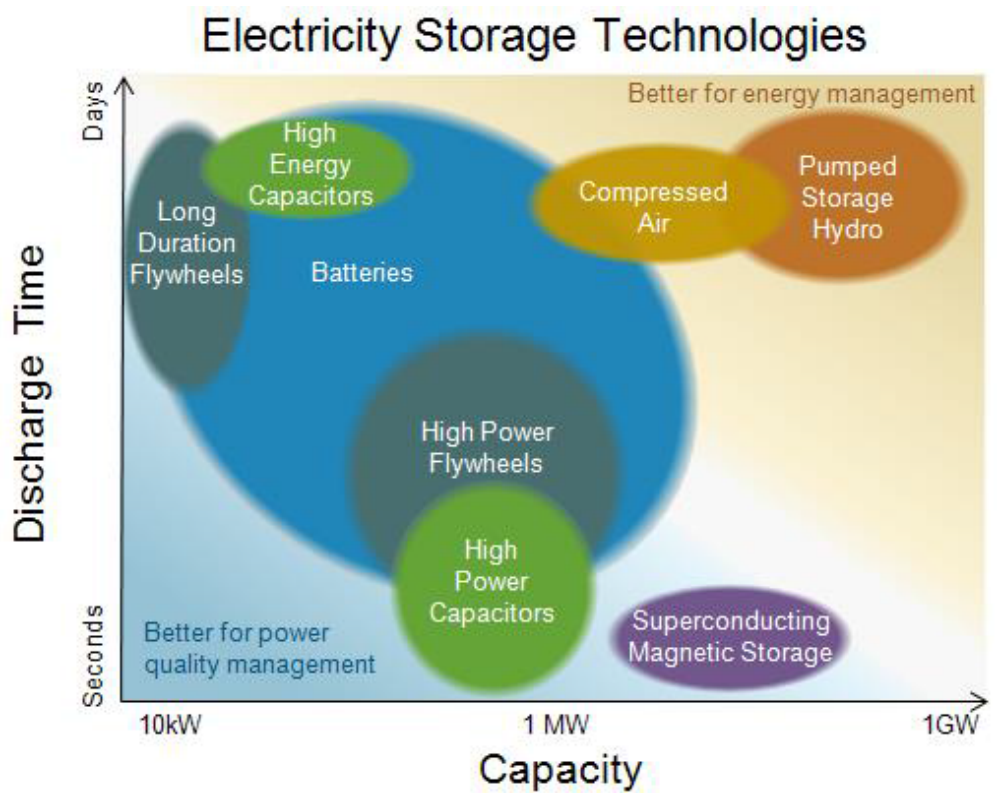

Figure 2 Comparison of different storage technologies in terms of storage time and energy storage capacity

As seen in figure 2, the compressed air energy storage system has the highest production capacity and the highest response time between energy storage methods.

This article focuses on the general principles, location, disadvantages and advantages of CAES in the second part. In the third section, which is the main purpose of this article, system features and improvement and better management of CAES systems will be exsmined. In the fourth section, the results and conclusion of the article is presented.

\subsection{Performance}

\section{Electrical energy saving in compressed air}

This method, with the use of a compressor, uses energy in the non-peak time for compressing air and storing it at high pressure (typically about 40-75 times) in an air tank (Lund, et al., 2009). During the discharge phase at peak times, compressed air is dispersed in the combustion chamber and combined with oil or gas until it finally turns on a gas turbine generating electrical energy. The system with 50-300 MW has an efficiency about 85\%. Figure 3 shows the block diagram of a CAES system (Grazzini and Milazzo 2008; Lund et al. 2009)

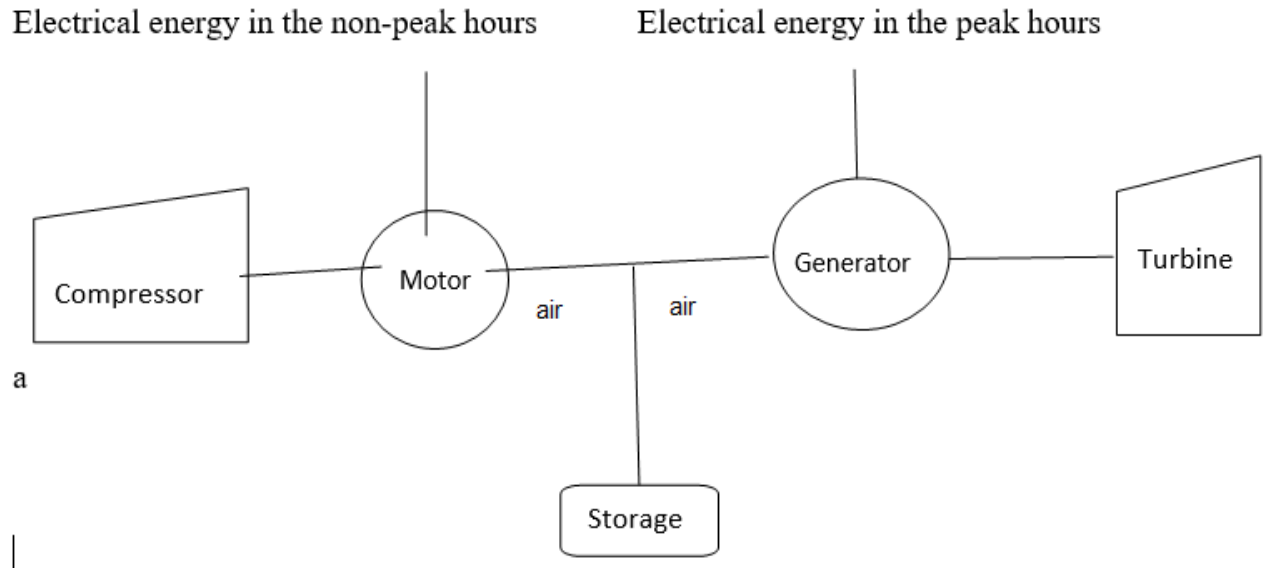

Figure 3 A simple schema of the CAES system

The CAES consists of four main parts that are shown in figure 4. These parts are mentioned in the following paragraph.

1. a motor-generator

2. Air Compressor

3. gas turbines

4. An underground reservoir for storing compressed air. (Jewitt 2005) 


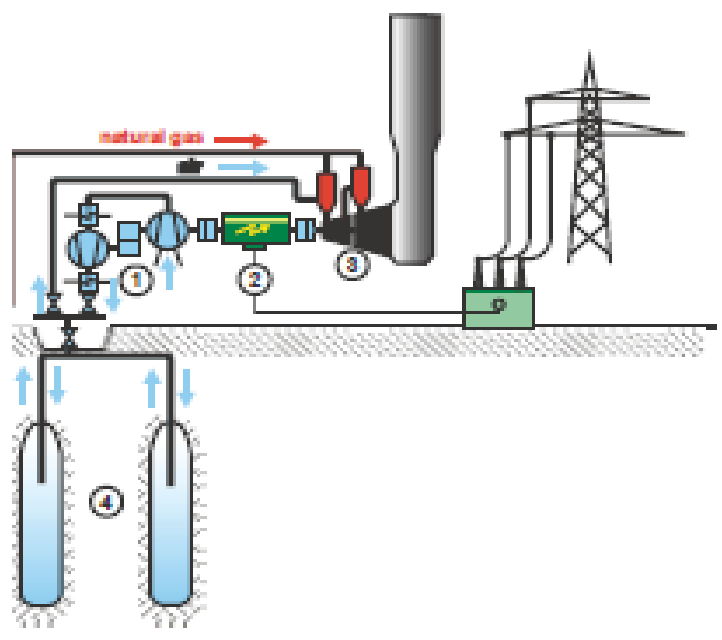

Figure 4 A sample of design of a CAES

Compressors are driven by combustion engines whose energy requirements depend on the system efficiency and the power needed to compress the air. Caverns are used to store compressed air, but they can neutralize the pressure fluctuations that occur in the network and maintain a constant pressure. Filters absorb moisture, oil and dust and prepare compressed air for the operation of pneumatic tools and devices that require clean air without moisture, and pipes carry compressed air to consumer equipment. Choosing, designing, repairing, optimizing each of these elements has an enormous effect on energy consumption. Energy management opportunities are linked to reducing the amount of work of compressing, heat recovery, and reducing the potential energy loss of stored air. So, understanding the system and checking the current status and comparing it to optimal situations is one of the tools of energy management. In a typical gas turbine, hot gas is produced at high pressures, and about two thirds of the gross domestic product of the power plant is used for compressor and turbine operation. A CAES system separates a compressor and a turbine, and an air compressor operates for compression and storage of air in the underground tank during non-peak hours (cheap electricity).

The heat generated during compression of the air can be stored and used to pre-heat the compressed air, thereby increasing the efficiency and significant increase in the storage of compressed air in underground caverns.

\subsection{Choosing the area for CAES system}

The EES system can be used throughout the energy sector, including supply, transmission, distribution, and demand. The best place to storage technology depends on the capabilities expected of the energy system from supply to consumption. In addition, developments in networks and other new technologies will affect the optimal location of these storage devices. Because of this fact that a large amount of energy generated by generators is used in power plants for rotating compressors and is wasted in their own system, the idea of building CAES power plants in areas where groundwater reservoirs can be used is suggested.

Storage tanks are classified into three different geological structures: rock caves composed of hard and impenetrable and limestone rocks (Denholm and Holloway 2005; Sears 2004); salt caves created by solution or drying of the mines of the organization salt; porous conductive tanks made of water-based aquifers or discharged gas tanks or crude oil fields. The geological characteristics of each of these reservoirs and the selection of each one depends on the conditions of use and cost and should have the proper geological features and a suitable location for the project, these factors are mentioned in the following paragraphs.

\section{A. Proximity to transmission lines}

Due to the dependence of CAES on the power network, the more power plants are closer to the energy transmission lines, the closer they will be to the load centers. This issue is important for EES systems, because there are losses in energy transmission in both storage and energy recovery situations. (Sears 2004)

\section{B. Access to natural gas}

The installation of CAES power plants requires fossil fuels, so the construction of the power plant should be selected wherever is close to natural gas sources and gas power plants (Chen et al., 2009)

\section{Noise}

Due to the high noise of compressors and turbines at the CAES facility, the construction of projects should be in a place where the sound from turbines and compressors does not adversely affect the equipment and the surrounding environment. 
These reservoirs should have the geophysical characteristics including pressure bearing capacity and the permeability of the reservoirs and the type of arch of the reservoirs.

1. No leakage: The reservoir must have the ability to withstand high pressure and no leakage in the reservoirs to store air. With new technologies, it is possible to scan the reservoir before the operation to ensure that there are no gaps and frail structures of reservoir.

2 Pressure bearing capacity: Due to the fact that compressed air storage systems operate to save more air and receive more energy and efficiency up to $80 \%$, at high pressures (40 to 75 times), the drainage reservoirs must be able to bear these high pressures

3. Stone arches: The presence of U-shaped arches in the U-inverted form prevents the air from escaping and leaking from the upper layers. Therefore, before construction, geological conditions and reservoir arches should be examined and simulated.

\subsection{Advantages}

Compressed air is used because of its high security, flexibility and eco-friendliness in a variety of ways. CAES systems are designed for daily cycle design and are effectively used in loading conditions. As a result, CAES has the following advantages: Network support services, such as reducing peak load, frequency adjustments.

One of the gials of the EES system is to eliminate the simultaneity of production and consumption in the network, which the CAES system does well.

1. CAES power plants can respond to load changes to respond to future loads;

2. Connection of CAES systems to various renewable energy sources can increase capacity and improve environmental characteristics;

3. CAES has a long storage period and low capital costs;

4. compressed air has a low risk;

5. devices that work with it do not require much repair;

6. Reducing environmental pollution and reducing greenhouse gas emissions;

7. The compressed air does not cause explosions and fires;

8. Air availability and the use of clean air in compression.

\subsection{Disadvantages}

In the CAES mechanism similar to any other technology of energy conversion, wate of energy is inevitable, and there are some disadvantages that mention of some of them are necessary. The main obstacle to the implementation of the CAES is the dependence on the favorable geography, such as cave that are good economically to power plants includes rock mines, salt caves, aquifers, or low-consumption fields. In addition, CAES is not an independent system and needs to connect to a gas turbine power plants.

At power plants that compressed air are used, a lot of energy is wasted when using electricity to compress air in the form of heat and when it is used to generate electricity from compressed air.

\subsection{Establishment}

Historically, the use of CAES is began in 1949, when Stal Laval recorded the first patent for CAES, which used compressed air to store air. Although CAES has become an old and commercial energy storage technology, there are only two CAES around the world. One in Hanover in Germany, which is the oldest CAES system. This system has been in operation since 1978. The Huntorf CAES system is a 290 megawatt and $50 \mathrm{GHz}$ unit. The size of the cave, located in an underground salt puddle and located about 600 meters underground, is about 310000 cubic meters. Compression is achieved through the use of 60 MW compressors with a maximum pressure of $10 \mathrm{MPa}$. Since its installation, the company has demonstrated high level performance and reliability of 99\%. (Gardner and Haynes 2007)

The second CARS plant, owned by Alabama Energy Cooperative (AEC) in Mclntosh, Alabama has been in operation since 1991. The CAES system has a pressure of 7.5 mega pps in a salt cavern 450 meters below the surface with a storage capacity of more than 500,000 cubic meters, with a production capacity of 110 megawatts. The McIntosh system reduces $25 \%$ of fuel consumption in compared to the Huntorf CAES system using re-use of the heat energy from the gas turbine. (Gardner and Haynes 2007)

\subsection{Types of Application Patterns of CAES}

There are currently three patterns for using CAES systems. These three models have completed in the three generations of compressed air technology and some have been operational.

\section{First generation CAES technology}

This technology is scientifically proven and similar to a gas power plant, such as the Huntorf CAES system. 


\section{Second generation CAES technology}

The second-generation technology is similar to the first generation, with this difference that some changes and developments are taking place in the design that uses a conventional gas turbine, and residual air in turbine for preheating the air before placing in the expander, which reduces the heat rate and increases the returns (efficiency in the second generation is $54 \%$ and improved in comparison with the first generation, which is 48 $50 \%)$,

\section{third generation CAES technology}

CAES in this generation is called adiabatic CAES plants, and the focus of recent research is related to these fields. In this technology, the process of converting storage air to electrical power is not used from any fuel, cooling compressors and heating the stored air to generate power is possible with storing thermal energy.

\section{Improvement of management of CAES systems}

One of the strategic goals of CAES system is to optimize energy consumption. Because the ability of electrical power production is limited due to the high cost of investment, therefore, increasing the efficiency of existing power plants has a significant effect on reducing costs and investment in the production, transmission and distribution of electrical energy. One of the ways to achieve these goals is to use load and energy management techniques. Energy management opportunities are linked to reducing the amount of work of compressing, heat recovery, and reducing the potential energy loss of stored air. So, understanding the system and checking the current status and comparing it to optimal situations is one of the tools of energy management.

Effective performance in the CAES system is affected by the following factors, and it is necessary to examine the following factors to optimize and increase the efficiency.

1. Choosing the proper type and size of the compressor (rotary, reciprocating, etc.);

2. Providing input air at the lowest possible temperature;

3. minimize system pressure drop;

4. controlling and removing leaks;

5. heat recovery;

6. compressed air purification and storage systems;

7. System for the correct distribution and transfer of compressed air to the consumer unit.

\subsection{Compressor}

Compressors increase air pressure in one or several steps and transfer energy to the air. As a result of reduction in the volume of compressed air, its temperature and density increase. Several factors are important in the selection of compressors, the main factors of which are compressed air capacity and compressed air produced in the shortest time, quality of produced compressed air and primary capital. Compressors are divided into two general categories of displacement compressors and dynamic compressors. In the displacement compressors, the gas is drawn into the chamber and, after compression, by a piston, goes back and forth out of the chamber. Dynamic compressors also works in this way that the turbine blades first speed up the gas and then suddenly reduces the speed and converts it to pressure.

3.1.1 The methods for optimization energy consumption in compressors

There are several ways to increase the efficiency and quality of compressor work, some of which cost more, and others are less costly with better management. These methods include:

A) Expensuve methods for improving compressors:

1. Replacing the compressors with similar comperssors that have more efficiency;

2. Installation of FC;

3. Having a precise and modern system for controlling the compressor improves its efficient quality;

4. Cooling the inputting air into the system, which reduces the energy consumption of the system;

5. Selection of suitable Electromotor from the aspect of standard for installation on compressors;

B) Low-cost methods for improving compressor work:

1. Evaluation of compressor function;

2. Proper planning for maintenance and repair;

3. Power factor correction;

4. Proper installation and location for the installation of compressors in terms of energy consumption and lifetime of the system is very useful. 


\subsection{Providing inputting air at the lowest possible temperature}

The volume of compressed air is directly related to its temperature. In general, the lower the temperature of the air entering the compressor, the lower the energy consumption in the compressor, and on the contrary, with increasing air temperature and in warm seasons, the power and energy required with the compressor to compress the air increases. Compressors need to do more to compress the hot air, saving up to $1 \%$ of energy consumption for every $3{ }^{\circ}$ decrease in the temperature of inputting air into the compressor. In table 1 , information about the energy required for an air compressor, based on temperature of the inputting air is shown.

Table 1 The percentage of saved energy in terms of temperature of inputting air into the compressor

\begin{tabular}{|l|l|l|}
\hline Saved energy & Rate of air volume* $^{*}$ & Temperature of the inputting air \\
\hline$\% 7 / 5$ & 930 & 0 \\
\hline$\% 5 / 7$ & 945 & 5 \\
\hline$\% 3 / 8$ & 960 & 10 \\
\hline$\% 2$ & 980 & 15 \\
\hline---- & 1000 & 21 \\
\hline$\% 2$ & 1020 & 25 \\
\hline$\% 4$ & 1040 & 30 \\
\hline$\% 5 / 8$ & 1060 & 35 \\
\hline$\% 7 / 5$ & 1080 & 40 \\
\hline
\end{tabular}

* Based on the flow of 1000 cubic meters of air at $21^{\circ} \mathrm{C}$

\subsection{Minimizing system pressure}

Pressure drop is a measure of pressure drop from the production stage to the consumption stage. High pressure drop causes poor performance or system failure and more energy consumption. In order to minimize the pressure drop, the best transmission and networking conditions in the design of the system would be considered and in maintaining and utilization of the system should be tired. In the compressed air system, pressure drop factors are included cooler systems, filters, humidifiers, dryers, and inappropriate networking. Therefore, the use of appropriate tools and components for reducing the path and distance and reducing networking reduce the pressure drop. For every 0.5 bar, the compressed air pressure is reduced about $4 \%$ and for every 1 bar reduced in compressed air pressure produces, $6 \%$ energy is saved.

\section{4 compressed air leaks}

Leaks are considered as the main source of energy loss in compressed air systems, which form about $20-30 \%$ of the output. Leaks cause a loss of pressure and thus reduce system efficiency, and leaks increases the work of compressor thus increases energy costs and costs ofmaintaining and repairing the system. Therefore, more than $10 \%$ of leaks can be reducedwith planning and finding leaks and eliminating them. The first thing that has to be done to eliminate leaks is to measure leaks in the network.

When the CAES system is not used in a power plant, we measure and record the amount of under load and the time to reach the nominal pressure value, and repeat it to reach to the compressor function, and thus we calculate the leakage rate. Table 2 provides information on the size of pores and leaks and their number.

Table 2 Leakage rate in CAES systems according to the number and size of pores

\begin{tabular}{|l|l|l|l|}
\hline $\begin{array}{l}\text { Air leakage (liters } \\
\text { per second) }\end{array}$ & $\begin{array}{l}\text { Leakage rate per pore (at the } \\
\text { pressure of8 tomes) }\end{array}$ & Number of pores & $\begin{array}{l}\text { Diameter of pores } \\
(\mathrm{mm})\end{array}$ \\
\hline $3 / 3$ & $0 / 33$ & 10 & $0 / 5$ \\
\hline $32 / 5$ & $1 / 30$ & 25 & 1 \\
\hline 110 & $5 / 1$ & 20 & 2 \\
\hline 185 & $11 / 5$ & 15 & 3 \\
\hline
\end{tabular}

After obtaining the leakage rate, we look at the cause of the leak, which can be related to design, analytical, operation parts or repair.
A) Analytical part
1.threaded connections;
2. faulty threads;
3. poor installation of gaskets;
4. high temperatures. 


\section{B) Design}

1. not fastening;

2. no connection;

3. inappropriate materials;

4. Connection under pressure.

\section{C) Vibration}

1. additional pressure;

2. poor operational design;

3. extra loads;

4. poor repair and assembly.

5. damaged parts

\subsection{Heat recovery}

In the CAES systems, the possibility of heat recovery should be examined. The compressors are cooled by water or air and the best way to recycle and apply heat and return it to the system should be studied. More than $50 \%$ of the power consumption in air compressors is converted to heat.

\subsection{Compressed air purification systems}

Compressed air, produced by compressors, needs to be filtered to enter the distribution network. These filters are often absorbent of water, dust and oil, and other microbial contaminants that are often installed at the outlet of the compressors or at the beginning of the production process line that increase the efficiency and lifetime of the machine. Not usingfilters can cause serious damage to the system. There are several methods to increase efficiency, some of which include:

1. First, the quality of inputting air is examined and then the filter type is selected according to the type of need.

2. With pressure measurement on the two sides of the filter (before and after the filter) the amount of dirt and the filtration mass of the filter can be mesured.

3. Useing modern filters.

4. Checking the inlet and outlet diameter of the filter (if the outlet diameter is less, the air velocity will increase and therefore the pressure drop is occured)

5. Use the dryers in the right place

\subsection{Distribution of compressed air}

To transfer compressed air to the system, a network of pipes is used, the length and diameter of the lines should be appropriate to the type of system and work.

- The amount of the volume of airflow - Checking the pressure and flow in different locations, and the space that requires the compressed air (pressure) and the place that requires high air (Dubai) should be considered.

- Pipeline length

- Allowed pressure drop - To measure the pressure drop in a distribution network, firstly, the valves, flanges, knees and joints, and the equivalent of the pipe, should be converted, and then, using the relevant tables, the pressure drop should be calculated.

- Number of split points and bottlenecks in the network

\section{Conclusion}

ESS systems can be used for energy management, power quality or as an energy interface. In this paper, principles, performance, installation and status of research and development of compressed air energy storage systems have been investigated. The CAES system will reduce peak load pressure on the power system, will cause frequency stabilization and will increase network efficiency.

In addition in this paper, the features and improvements and better management of CAES systems are examined, and different solutions for each step are provided. According to the study that is done, improvements should be made in two steps. 1- Improvement of energy in the production and injection system of compressed air, which includes: Compressors, FC, Filtration systems. 2. Improvement of energy after compressed air production and transfer to the system and power plant, which includes: removal of leaks - the use of heat generated - the proper use of the transmission system. With a true examination, about $20 \%$ of energy can be saved.

In the end, according to the importance of compact air storage and energy recovery, continuous and complete management of the system and the inclusive cooperation of all personnel in the implementation of the correct system management are necessary. 


\section{Reference}

[1] Chen, Haisheng, et al. 2009 Progress in electrical energy storage system: A critical review. Progress in Natural Science 19(3):291-312.

[2] Denholm, Paul, and Tracey Holloway 2005 Improved accounting of emissions from utility energy storage system operation: ACS Publications.

[3] Dincer, Ibrahim, and Marc Rosen 2002 Thermal energy storage: systems and applications: John Wiley \& Sons.

[4] DTI, D 2004 Status of electrical energy storage systems. Report DTI (Department of Trade \& Industry).

[5] Ellabban, Omar, Haitham Abu-Rub, and Frede Blaabjerg 2014 Renewable energy resources: Current status, future prospects and their enabling technology. Renewable and Sustainable Energy Reviews 39:748-764.

[6] Gardner, J, and T Haynes 2007 Overview of Compressed Air Energy Storage. Office of Energy Research. Policy and Campus Sustainability.

[7] Grazzini, Giuseppe, and Adriano Milazzo 2008 Thermodynamic analysis of CAES/TES systems for renewable energy plants. Renewable Energy 33(9):1998-2006.

[8] Jewitt, J 2005 Impact of CAES on Wind in Tx, OK and NM. Annual peer review meeting of DOE energy storage systems research. San Francisco, USA, 2005, pp. 1-16.

[9] Lund, Henrik, et al. 2009 Optimal operation strategies of compressed air energy storage (CAES) on electricity spot markets with fluctuating prices. Applied thermal engineering 29(5):799-806.

[10] McLarnon, Frank R, and Elton J Cairns 1989 Energy storage. Annual review of energy 14(1):241-271.

[11] Sears, John R 2004 TEX: The next generation of energy storage technology. Telecommunications Energy Conference, 2004. INTELEC 2004. 26th Annual International, 2004, pp. 218-222. IEEE. 